\title{
Motrivivancia

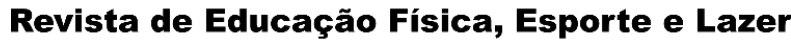 \\ LaboMídia
}

\section{Compreensão de dança dos estudantes da Asces-Unita a partir do projeto de extensão Brincantes do Agreste}

\section{RESUMO}

O estudo objetivou compreender o entendimento sobre dança popular dos participantes do projeto de extensão Brincantes do Agreste e os impactos da extensão universitária no seu processo de formação. Essa pesquisa de caráter exploratório, descritivo e quali-quantitativo contou com 18 participantes que responderam a um questionário, além disso houve uma observação assistemática em um dos ensaios do grupo de dança. Os resultados apontaram que os participantes tiveram seus conhecimentos sobre dança popular ampliados; o projeto assumiu um papel relevante no encontro entre teoria e prática dos saberes aprendidos na graduação; o contato com a comunidade permitiu expandir suas experiências e percepções do papel da dança na sociedade. Tais investigações contribuem para uma discussão acerca da extensão universitária no processo de formação, no sentido de desenvolver saberes, experiências e impressões decorrentes de uma prática articulada com a realidade do conhecimento.

PALAVRAS-CHAVE: Dança; Diversidade cultural; Extensão universitária; Corpo

Esther Santos Mendes

Graduanda em Licenciatura em Educação Física Associação Caruaruense de Ensino Superior ASCES/UNITA, Departamento de Educação

Física, Caruaru, Pernambuco, Brasil esther.ssantos07@hotmail.com

(대 htps://orcid.org/0000-0003-1481-1202

Viviane Maria Moraes de Oliveira Mestre em Saúde da Criança e do Adolescente Associação Caruaruense de Ensino Superior ASCES/UNITA, Departamento de Educação Física, Caruaru, Pernambuco, Brasil vivimmo@hotmail.com

[D https://orcid.org/0000-0003-4242-4912

Maria Williane Gomes Xavier Graduanda em Licenciatura em Educação Física Associação Caruaruense de Ensino Superior ASCES/UNITA, Departamento de Educação

Física, Caruaru, Pernambuco, Brasil

williannygomes18@gmail.com

ำ https://orcid.org/0000-0002-9184-9186

Ana Paula Rodrigues Figuerôa Doutora em Saúde da Criança e do Adolescente Associação Caruaruense de Ensino Superior ASCES/UNITA, Departamento de Educação

Física, Caruaru, Pernambuco, Brasil anafigueiroa@asces.edu.br

(1) https://orcid.org/0000-0003-4875-5253 


\title{
Asces-Unita's students comprehension of dance through the extension project Brincantes do Agreste
}

\begin{abstract}
The study aimed to comprehend the understanding about popular dance by participants in the Dance in Agreste extension project and the impacts of university extension on their education process. This exploratory, descriptive and quali-quantitative research involved 18 participants who answered a questionnaire, in addition there was an unsystematic observation in one of the dance group's rehearsals. The results showed that the participants had their knowledge about popular dance expanded; the project took on a relevant role in the encounter between theory and practice of the knowledge learned during graduation; contact with the community allowed participants to expand their experiences and perceptions of the role of dance in society. Such investigations contribute to a discussion about university extension in the education process, in the sense of developing knowledge, experiences and impressions resulting from a practice articulated with the reality of knowledge
\end{abstract}

KEYWORDS: Dance; Cultural diversity; University extension; Body

\section{Compreensión de la danza de los estudiantes de la Asces-Unita a partir del proyecto de extensión Brincantes do Agreste}

\section{RESUMEN}

El estudio tuvo como objetivo comprender la comprensión de la danza popular por parte de los participantes en el proyecto de extensión Dance in Agreste y los impactos de la extensión universitaria en su proceso de capacitación. Esta investigación exploratoria, descriptiva y cualitativa cuantitativa involucró a 18 participantes que respondieron un cuestionario, además hubo una observación no sistemática en uno de los ensayos del grupo de baile. Los resultados mostraron que los participantes tenían un mayor conocimiento sobre la danza popular; el proyecto asumió un papel relevante en el encuentro entre la teoría y la práctica del conocimiento aprendido durante la graduación; El contacto con la comunidad le permitió ampliar sus experiencias y percepciones sobre el papel de la danza en la sociedad. Dichas investigaciones contribuyen a una discusión sobre la extensión universitaria en el proceso de capacitación, en el sentido de desarrollar conocimiento, experiencias e impresiones resultantes de una práctica articulada con la realidad del conocimiento

PALABRAS-CLAVE: Danza; Diversidad cultural; Extensión universitaria; Cuerpo 


\section{INTRODUÇÃO}

Ao longo da história, a extensão universitária tem recebido diversas influências e concepções. Com a lei $n^{0} 5.540 / 68$ a extensão passou a ser mais um componente fundamental à universidade atrelado ao ensino e à pesquisa. $\mathrm{O}$ art. 20 dessa lei afirma que "As universidades e os estabelecimentos isolados de ensino superior estenderão à comunidade, sob forma de cursos e serviços especiais, as atividades de ensino e os resultados da pesquisa que lhes são inerentes". Consequentemente, a universidade não seria apenas formadora de profissionais de nível universitário, mas passaria a se comprometer com a sociedade por meio da prestação de serviços e contribuindo para o bem-estar social.

A importância das atividades de extensão reside na indispensabilidade de transformar o processo de ensino-aprendizagem, tornando-o mais expressivo mediante experiências e diálogos entre conhecimentos interdisciplinares e confronto entre a teoria e prática, construindo uma relação entre o saber científico e os reais interesses da sociedade. As trocas de experiências entre os discentes e a sociedade são matéria-prima para o conhecimento, para a reflexão e para a transformação, como aponta Castro $(2004$, p.14) “[...] no caso da extensão o que percebemos é que ela produz conhecimento a partir da experiência e assim tem uma capacidade de narrar sobre o seu fazer [...]" ademais, somente um conhecimento produzido numa relação emancipatória é capaz de agregar valores. Essa realidade só é possível numa universidade capaz de reconhecer a participação autêntica dos cidadãos da comunidade.

Sendo assim, foi eleito como alvo desta pesquisa o projeto de extensão Brincantes do Agreste, desenvolvido no Centro Universitário Tabosa de Almeida (ASCES-UNITA) desde 2017, no qual, a partir de produções artísticas e culturais e com o intuito de desenvolver e potencializar a apreciação pela dança, os extensionistas desenvolvem atividades como aulas de danças populares de Pernambuco e composições coreográficas na instituição e em ações junto à comunidade atendida pelo projeto. Para Nascimento (2012) a área da dança é privilegiada para uma abordagem sobre pluralidade cultural, porque apresenta no corpo em si a diversidade tanto na forma como um indivíduo se movimenta, quanto na estrutura do seu físico, onde se destacam aspectos socioculturais e políticos.

No espaço da extensão, a vivência da dança amplia o olhar artístico e a forma como essa arte dialoga com o mundo através das experiências dentro e fora do ambiente acadêmico, onde os saberes se converterão em um aprendizado rico para a vida profissional e pessoal do discente. Portanto, torna-se fundamental que esse discente seja "[..] capaz de desenvolver a dança e lidar com as implicações advindas da experiência[...]” (KLEINUBING, PAULA, FRANCISCHI, 2016, p. 4). 
As ações realizadas num projeto de extensão, por serem distintas daquelas do tempo-espaço das aulas regulares, permitem situações diferenciadas; nos contextos de projetos de extensão em dança essas situações ampliam o entendimento dos discentes sobre concepções sobre o próprio corpo, a técnica e os espaços ditos destinados à sua prática (KLEINUBING; DAL CIN, 2020). Síveres (2008) afirma que a extensão deve se constituir numa ambiência que propicia que o processo de ensino-aprendizagem se transforme num projeto de vida. $\mathrm{O}$ ensino e aprendizagem da dança, portanto, não se exclui dessa realidade.

Assim, torna-se essencial repensar as práticas de formação universitária a partir de um dos eixos que a estrutura: a extensão. E a partir das pesquisas reafirmar sua importância e relação cada vez maior com áreas do conhecimento diversas agregando saberes e valores. Na busca por interligar as ações do ensino, pesquisa e extensão com as necessidades da sociedade atual, é indispensável que se façam constantes discussões a fim de superar uma prática extensionista meramente assistencialista e propor com que esse eixo que compõe a universidade realize diferentes intervenções orientadas por princípios de compromisso e transformação social.

Conforme Coelho (2014) as aprendizagens viabilizadas pela extensão universitária só serão apropriadas de forma criativa e motivadora quando tais práticas não renunciarem a uma reflexão conjunta e a uma sistematização da crítica e autocrítica pelos sujeitos internos e externos à universidade. Repensar as práticas de formação extensionistas é, pois, repensar um saber que deve ser construído "[...] dialeticamente de fora para dentro e de dentro para fora". (MARINHO et al., 2019, p.136).

Diante disso, objetivou-se compreender o entendimento acerca das danças populares pelos discentes que fazem parte do Brincantes do Agreste a partir de sua inserção, uma vez que o projeto possibilita desenvolver a aprendizagem deste conteúdo, redescobrindo-o juntamente com a comunidade, permitindo aos indivíduos, pelo seu envolvimento nesse processo, construírem suas próprias concepções de dança. Ademais, os benefícios através da prática da dança não apenas perpassam as condições de manutenção da saúde física e psicológica, mas reconhece, mediante toda sua carga cultural, a história de um povo, questões sociais, econômicas e políticas, em virtude de sua pluralidade de significados, de expressões e linguagens. 


\section{BASES TEÓRICAS}

\section{Conceituando as danças populares do Nordeste}

As danças receberam diversos significados ao longo do tempo devido às transformações sociais. De acordo com Amaral (2009, p.s/n) “[...] era parte viva e funcional das comunidades, uma verdadeira reação e interação com o universo no qual se vivia".

O conceito de cultura popular ou folclórica pode ser melhor entendido por meio da obra de Brandão (1983) "O que é folclore", nela o autor apresenta quatro elementos fundamentais que caracterizam essas manifestações: a) a origem de classe: faz parte de um povo considerado hierarquicamente inferior; b) coletivização anônima da criação pessoal: os conhecimentos foram aceitos e retraduzidos como um saber coletivo; c) a persistência no tempo: há uma certa estrutura que é determinante e que apesar das modificações ao longo da história, não invalidam o original e; d) a aprendizagem informal: os saberes populares são transmitidos ao longo das gerações em espaços não-formais. São esses elementos que validam as manifestações humanas como fatos populares.

As danças consideradas folclóricas ou populares, segundo Oliveira (1991), são aprendidas por imitação direta e não por situações formais, essas danças são típicas de cada região ou país e, por razões históricas, não foram universalizadas. Assim, a manifestação corporal das gerações nas suas diversas ocasiões traz consigo intencionalidades e significados, ou seja, o modo com o qual determinado grupo social dança possibilita o conhecimento sobre a sua cultura, sua história.

Dentro desse contexto insere-se a dança popular pernambucana, a qual, segundo Oliveira (2017) apresenta nos passos do frevo, por exemplo, movimentos que eram usados para defesa e ataque pelos capoeiristas ao longo da história, demonstrando que a dança apresenta em seu contexto uma bagagem de significados, uma herança cultural e histórica transformando-se em Patrimônio Imaterial da Humanidade.

\section{Dança e promoção da saúde}

As práticas corporais são ações que contribuem para a saúde e qualidade de vida da população. Essas práticas estão presentes na Portaria n ${ }^{\circ} 2446$ de 11 de Novembro de 2014, que redefine a Política Nacional de Promoção da Saúde (PNPS), onde em seu art. 10 incorporam “[...] brincadeiras, jogos, danças populares, dentre outras práticas", além de apontar em suas diretrizes a promoção da saúde como sendo parte fundamental da melhoria da qualidade de vida. Para o PNPS, a promoção da saúde é conceituada como uma estratégia articulada de construções de ações que 
possibilitem responder às necessidades da saúde social. Posto isto, as danças atendem aos preceitos do PNPS proporcionando benefícios para a qualidade de vida e o desenvolvimento físico, social e emocional dos seus praticantes.

Segundo Szuster (2011) a dança tem influência sobre três domínios da natureza humana, que são o físiológico, o afetivo e o cognitivo, atuando como fator motivador a manter a vida e a alegria por ser versátil e lúdica. Tratando cada um desses domínios respectivamente, a dança permite um grande trabalho dos movimentos do sistema musculoesquelético, bem como, desenvolve a coordenação e o ritmo; adquire-se consciência de si e do outro por meio dos movimentos coreográficos e por fim, permite o desenvolvimento da memória, criatividade, concentração e atenção.

$\mathrm{Na}$ dança "[..] torna-se possível reconhecer a linguagem do corpo que fala sem o som das palavras, é o corpo que se apresenta e se expande ao mundo para conhecê-lo, reconhecê-lo e dele melhor se relacionar [..] (ANDRADE et al., 2015, p.232). Para Nanni (2005) as possibilidades de movimento e formas de interação fazem com que o indivíduo dançante aperfeiçoe sua prática ampliando sua capacidade expressiva, além disso exercem um papel indispensável no desenvolvimento das percepções de cada um sobre si, influenciando tanto o desenvolvimento de atitudes emocionais quanto na estruturação da identidade do indivíduo e contribuindo para a construção de sua autonomia. Andrade et al. (2015, p. 232) acrescentam que nesse processo interpessoal em que os participantes se envolvem por meio da dança há "[..] acolhimento, valorização, inclusão em grupo, respeito à individualidade, compromisso pessoal, envolvimento do grupo, experiência na troca interpessoal no eixo vivências.”.

Sendo assim, a dança é uma atividade que contribui para a saúde das pessoas nos aspectos sociais, psicológicos, motores e afetivos, como afirma Marbá, Silva e Guimarães (2016). O bemestar por ela proporcionado está associado a fatores como a aquisição de capacidades físicas, autoestima e o desenvolvimento de relações interpessoais.

\section{Projetos de Extensão e interrelações: uma construção necessária}

O alicerce sobre o qual se desenvolve a educação superior brasileira é constituído de três funções indissociáveis, segundo o art. 207 da Constituição Federal de 1988: o ensino, a pesquisa e a extensão. Tais princípios são essenciais para a qualidade e identidade da educação universitária. A Lei de Diretrizes e Bases da Educação Nacional 93.94/1996 (LDBEN), no art. 43 ratifica a promoção da extensão na educação superior visando a difusão do progresso cultural e científico gerado nas instituições. 
Os anos finais de 1980 marcaram a constituição do Fórum de Pró-Reitores de Extensão Universitária. Em decorrência dele foram elaborados primeiramente o I Plano Nacional de Extensão e, posteriormente, o Programa de Extensão Universitária (PROEXT), visando apoiar as instituições públicas de educação superior no desenvolvimento de seus projetos de extensão universitária. Atualmente, a extensão tem ganhado espaço nas universidades através de programas, sendo fator importante na carreira docente e nos currículos profissionais, como aponta DEUS (2017).

Benetti, Sousa e Souza (2015), sobre o papel da extensão na universidade, destacam as cinco diretrizes que fundamentam-na sendo estas: interação dialógica, que é a troca de saberes nas relações entre universidade e organizações sociais; interdisciplinaridade e interprofissionalidade, a integração das diversas áreas do conhecimento presentes na universidade; indissociabilidade ensinopesquisa-extensão, fortalecimento das ações extensionistas quando vinculadas à produção de conhecimento e ao processo pedagógico; impacto na formação do estudante, enriquece as experiências e saberes dos estudantes e, por fim, impacto na transformação social, que posiciona a universidade como agente de transformações e desenvolvimento social. Fundamentado nessas diretrizes, a extensão conduz a universidade a uma conduta de relações e mudanças do meio social impactando os processos de ensino, aprendizagem e intervenção na comunidade.

A extensão é o lugar onde o estudante se relaciona com a sociedade de forma efetiva e simultaneamente situa sua formação técnica com os desafios e necessidades reais que enfrentará. A extensão, portanto, “[...] deve possibilitar mais do que a formação de profissionais, mas uma formação para o exercício da cidadania” (SANTOS; ROCHA; PASSAGLIO, 2016, p. 25). Garcia, Bohn e Araújo (2013), destacam que ao ir além do espaço das salas de aula, a extensão oportuniza solidificar o conhecimento produzido na universidade através da articulação de saberes acadêmicos e sociais que promovem transformações no meio social e no desenvolvimento humano. Já em Ribeiro, Pontes e Silva (2017), a extensão universitária oportuniza o confronto de saberes plurais baseados em conhecimentos adquiridos nos mais diversos âmbitos sociais, ou seja, os saberes da sociedade serão articulados com o que foi estudado em sala de aula construindo dessa troca de aprendizado uma formação ética e comprometida.

Entretanto, Botomé (1996) citado por Santos, Rocha e Passaglio (2016), destaca que na extensão os estudantes não sejam apenas postos em contato com as necessidades sociais, de modo que a pesquisa e a extensão fiquem marginalizadas e alienadas de reflexão e do compromisso social com a sociedade; ao contrário, o vínculo da extensão com a pesquisa produz mudanças no fazer pedagógico tendo ambos (o pesquisador e o extensionista) o aprender no centro de suas ações.

Beneti, Sousa e Souza $(2015$, p.31) apontam que para que possamos considerar as ações como de fato extensionistas estas devem “[...]envolver obrigatoriamente a participação ativa dos 
estudantes, a coordenação de docentes ou técnicos administrativos e, sobretudo, as demandas dos demais setores da sociedade[...]". Quando a extensão universitária sugere um contato com a comunidade não se tem como função apenas levar o conhecimento, mas também se busca uma comunicação de saberes entre acadêmicos e a comunidade. A extensão produz no estudante uma mudança de consciência de uma "troca de conhecimentos" contrastando com uma mera transmissão de saberes do domínio dos acadêmicos (SANTOS; ROCHA; PASSAGLIO, 2016). As ações extensionistas devem ser percebidas, portanto, enquanto um processo de aprendizado.

Costa, Baiotto e Garces (2013, p.74) apontam que "[...] esses valores brotam a partir da vivência das diferenças, na reciprocidade das relações, ao nos colocarmos no lugar do outro ou ao se ter um novo olhar sobre o outro, $[. .$.$] ”. Desta forma, o conhecimento vinculado na universidade é$ confrontado na realidade vivida pelos estudantes e esses têm a oportunidade de promover reflexões e mudanças significativas mediante a extensão.

Sendo assim, a extensão universitária se sustenta na responsabilidade de, em interação com os diferentes setores da sociedade, produzir conhecimento e transformações significativas na comunidade. Para isso, é imprescindível a participação ativa de todos os membros dentro e fora da universidade fundamentados com o um compromisso ético e coletivo.

\section{DECISÕES METODOLÓGICAS}

No presente estudo foi realizada uma pesquisa de campo, o estudo tem caráter descritivo onde foram observadas as situações registrando suas variáveis para analisá-las sem a interferência nos dados obtidos. Esta pesquisa foi aprovada pelo Comitê de Ética em Pesquisa (Parecer $n^{\circ}$ 3.745.077/2019). Houve o consentimento dos envolvidos na pesquisa por meio do Termo de Consentimento Livre e Esclarecido (TCLE) e teve como instrumento de investigação a aplicação de um questionário on-line entre os meses de dezembro de 2019 a fevereiro de 2020 e observação assistemática.

A estruturação das perguntas se deu com questões referentes às experiências prévias com a dança, seguido das vivências no projeto e por fim dos saberes assimilados dos estudantes decorrentes da sua inserção como extensionistas. As possibilidades de respostas fechadas eram compostas por três alternativas $(a, b$ e c) onde nas perguntas seguia-se um raciocínio em que a alternativa a) tinha caráter afirmativo, a alternativa b) possuía caráter de negação e a alternativa c) apresentava uma resposta parcial ao questionamento referido. Nas duas últimas questões (de respostas abertas) o participante relatou como o projeto proporcionou uma melhor compreensão acerca das danças populares pernambucanas e sua opinião acerca do projeto como parte da extensão universitária, respectivamente. 
A população-alvo constituiu-se dos participantes do grupo de dança incorporado ao projeto de extensão Brincantes do Agreste. Este grupo é responsável pela composição e execução de coreografias e participação em eventos culturais na universidade e na comunidade da ASCESUNITA, sendo uma das vertentes do projeto de extensão. Participaram apenas aqueles devidamente inscritos no projeto e que possuíam frequência nas aulas/ensaios igual ou superior a $50 \%$ da carga horária semestral. Baseado nos seguintes critérios 18 estudantes foram elegidos.

Em seguida, foi realizada uma visita a um dos ensaios do projeto no mês de março de 2020 a fim de observar a dinâmica do grupo no decorrer do ensaio e coletar informações consideráveis que favorecessem o entendimento dos benefícios do projeto de dança popular aos discentes, através de anotações referentes à essas observações. A observação como instrumento da pesquisa para coletar dados permite identificar "o que" e "como" esta observação vai acontecer. Foi estabelecido como critério a maior ou menor interação entre os participantes proporcionadas pela dança, a contextualização dos passos aprendidos nas composições coreográficas e as atividades desenvolvidas compatíveis com a proposta do projeto. Os dados foram analisados segundo a técnica de análise de conteúdo de Laurence Bardin (2011), que objetiva focar nas mensagens e a partir delas construir categorias-temáticas a fim de confirmar os indicadores que permitem depreender sobre outra realidade que não a da mensagem propriamente dita.

Esses dados foram tratados numa abordagem quali-quantitativa, ou método misto no intuito de produzir informações e conhecimentos de uso mais efetivo. As informações coletadas foram divididas em categorias sendo estas: cultura popular, aquisição de conhecimentos, troca de experiências, relações interpessoais, saúde e autocuidado, criticidade e prática pedagógica. Baseado nelas foi construído uma tabela com frequência e percentual descrevendo a sua análise na contextualização dos resultados expressados na mesma.

\section{ANÁLISE}

A partir das respostas do questionário foram estruturados 4 quadros, sendo 1 com informações acerca das caracterizações dos discentes da pesquisa, 3 com o percentuais e frequências das respostas fechadas do questionário, elaborados com base na divisão das perguntas em três grandes categorias: experiências com danças, vivências no projeto de extensão e conhecimentos e saberes assimilados através deste. Além disso foi estruturada 1 tabela com a análise das categorias identificadas nas respostas abertas. Com relação às perguntas fechadas, foram observados os percentuais das respostas em cada alternativa marcada. Os detalhes da amostra são apresentados no quadro 1 abaixo. 
Quadro 1 - Características pessoais e acadêmicas dos estudantes

\begin{tabular}{|c|c|c|}
\hline Variável & Categoria & Quantitativo \\
\hline \multirow{3}{*}{ Idade } & Menor que 20 anos & 01 \\
\hline & De 20 a 29 & 15 \\
\hline & 30 anos ou mais & 02 \\
\hline \multirow{2}{*}{ Sexo } & Feminino & 10 \\
\hline & Masculino & 08 \\
\hline \multirow{3}{*}{$\begin{array}{l}\text { Participação no } \\
\text { projeto de extensão }\end{array}$} & Até 1 ano & 03 \\
\hline & De 1 a 2 anos & 09 \\
\hline & Mais de 2 anos & 06 \\
\hline \multirow{5}{*}{ Curso } & Farmácia & 01 \\
\hline & $\begin{array}{c}\text { Licenciatura em Educação } \\
\text { Física }\end{array}$ & 04 \\
\hline & $\begin{array}{c}\text { Bacharelado em Educação } \\
\text { Física }\end{array}$ & 11 \\
\hline & Biomedicina & 01 \\
\hline & Enfermagem & 01 \\
\hline
\end{tabular}

Fonte: a pesquisa (2020).

Dentro desse quantitativo $66,6 \%(12 / 18)$ responderam que já tiveram alguma experiência através de aulas, oficinas, minicursos, entre outras formas de aprendizagem formais; 27,7\% (5/18) já tiveram alguma experiência em espaços não formais de ensino das danças e apenas 5,5\% (1/18) não teve nenhuma experiência, como pode-se observar de forma mais detalhada no quadro 2 abaixo.

Quadro 2 - Experiências com danças

\begin{tabular}{|c|c|c|c|}
\hline $\begin{array}{l}\text { Perfil da } \\
\text { pergunta }\end{array}$ & Alternativas & $\begin{array}{l}\text { Frequênci } \\
\text { a }\end{array}$ & $(\%)$ \\
\hline \multirow{3}{*}{$\begin{array}{l}\text { Experiências } \\
\text { com a dança } \\
\text { antes da } \\
\text { inserção no } \\
\text { projeto. }\end{array}$} & $\begin{array}{l}\text { a)Já tive experiências com danças } \\
\text { (aulas, minicursos, } \\
\text { oficinas, entre outros). }\end{array}$ & 12 & 66,6 \\
\hline & $\begin{array}{l}\text { b)Não tive nenhuma experiência com } \\
\text { danças. }\end{array}$ & 1 & 5,5 \\
\hline & $\begin{array}{l}\text { c)Já tive algumas experiências } \\
\text { informais como, por exemplo, em } \\
\text { festividades na escola, em atividades } \\
\text { lúdicas, dinâmicas, entre outros }\end{array}$ & 5 & 27,7 \\
\hline \multirow{2}{*}{$\begin{array}{l}\text { Percepção } \\
\text { das } \\
\text { dificuldades } \\
\text { da prática da } \\
\text { dança pela } \\
\text { população }\end{array}$} & $\begin{array}{l}\text { a)Gênero, pessoas que acreditam que a } \\
\text { dança é destinada apenas às mulheres } \\
\text { e por isso não participam de nenhuma } \\
\text { prática relacionada a uma atividade } \\
\text { rítmica e expressiva. }\end{array}$ & 6 & 33,3 \\
\hline & $\begin{array}{l}\text { b)Idade, pessoas que acreditam ter } \\
\text { uma idade específica para a prática da }\end{array}$ & 0 & 0,0 \\
\hline
\end{tabular}




\begin{tabular}{|l|l|c|c|}
\hline dança. & & \\
\hline $\begin{array}{l}\text { c)Técnica, pessoas que acreditam que } \\
\text { para dançar é necessário ter uma } \\
\text { experiência prévia ou habilidades } \\
\text { corporais. }\end{array}$ & 12 & 66,6 \\
\hline
\end{tabular}

Fonte: a pesquisa (2020).

Os resultados mostraram que 100\% (18/18) deles afirmaram ter suas experiências com as danças populares ampliadas; esse mesmo quantitativo pôde ser constatado no que se refere ao resgate de elementos presentes nas danças populares em suas coreografias, ensaios e ações e quase todos, 94,4\% (17/18) declararam ter suas capacidades de expressão e comunicação aprimoradas. Notou-se também que $88,8 \%$ (16/18), declararam que foi possível relacionar os conhecimentos construídos no projeto com àqueles do seu curso de graduação e 94,4\% (17/18) apontaram como positivo o impacto das ações do projeto para a comunidade atendida. Essas informações encontramse detalhadas no quadro 3 abaixo.

Quadro 3 - Vivências no projeto de extensão

\begin{tabular}{|c|c|c|c|}
\hline $\begin{array}{l}\text { Perfil da } \\
\text { pergunta }\end{array}$ & Alternativas & $\begin{array}{l}\text { Frequênci } \\
\text { a }\end{array}$ & $(\%)$ \\
\hline \multirow{3}{*}{$\begin{array}{l}\text { Ampliação das } \\
\text { experiências } \\
\text { dos estudantes } \\
\text { sobre as danças } \\
\text { populares } \\
\text { posteriormente } \\
\text { à sua } \\
\text { participação. }\end{array}$} & $\begin{array}{l}\text { a)Sim, ampliou consideravelmente ao } \\
\text { permitir a descoberta de novas formas de } \\
\text { expressão e a diversidade das } \\
\text { manifestações culturais através da dança }\end{array}$ & 18 & 100 \\
\hline & $\begin{array}{l}\text { b)Não, o projeto de extensão não agregou } \\
\text { nenhum novo conhecimento }\end{array}$ & 0 & 0,0 \\
\hline & $\begin{array}{l}\text { c) Sim, parcialmente, já tinha um bom } \\
\text { conhecimento e/ou vivência com as } \\
\text { danças populares. }\end{array}$ & 0 & 0,0 \\
\hline \multirow{3}{*}{$\begin{array}{l}\text { Possibilidade } \\
\text { de colocar em } \\
\text { prática e } \\
\text { relacionar os } \\
\text { conhecimentos } \\
\text { estudados ao } \\
\text { curso de } \\
\text { graduação. }\end{array}$} & $\begin{array}{l}\text { a)Proporcionou conquistas e benefícios } \\
\text { ao ter a oportunidade de criar, } \\
\text { experimentar e/ou ensinar as danças } \\
\text { populares no seu sentido artístico e } \\
\text { cultural e aplicar esses saberes à minha } \\
\text { área de atuação. }\end{array}$ & 16 & 88,8 \\
\hline & $\begin{array}{l}\text { b)Não proporcionou nenhuma relação } \\
\text { com os conhecimentos estudados na } \\
\text { minha graduação. }\end{array}$ & 1 & 5,5 \\
\hline & $\begin{array}{l}\text { c)Proporcionou poucos conhecimentos e } \\
\text { experiências de modo que posso/pude } \\
\text { aplicar ou fazer relação parcialmente com } \\
\text { os conhecimentos estudados durante meu } \\
\text { curso de graduação }\end{array}$ & 1 & 5,5 \\
\hline \multirow{2}{*}{$\begin{array}{l}\text { Transformação } \\
\text { da realidade } \\
\text { social e/ou } \\
\text { acadêmica. }\end{array}$} & $\begin{array}{l}\text { a) Sim, por meio das ações do projeto foi } \\
\text { possível proporcionar à população à } \\
\text { vivência com as manifestações populares } \\
\text { e os benefícios da dança, bem como, a } \\
\text { apreciação da nossa cultural; }\end{array}$ & 17 & 94,4 \\
\hline & $\begin{array}{l}\text { b)Não foi possível intervir nem se pode } \\
\text { dizer que as ações do projeto }\end{array}$ & 0 & 0,0 \\
\hline
\end{tabular}




\begin{tabular}{|c|c|c|c|}
\hline & $\begin{array}{l}\text { proporcionaram nenhuma transformação } \\
\text { acadêmica ou social. }\end{array}$ & & \\
\hline & $\begin{array}{lll}\text { c)Parcialmente, as intervenções } & \text { e } \\
\text { transformações proporcionadas } & \text { à } \\
\text { comunidade atendidas são raras } & \\
\end{array}$ & 1 & 5,5 \\
\hline \multirow{3}{*}{$\begin{array}{l}\text { Resgate de } \\
\text { elementos } \\
\text { socioculturais } \\
\text { das danças } \\
\text { populares }\end{array}$} & $\begin{array}{l}\text { a)Pode-se resgatar as dimensões do saber } \\
\text { popular enunciado nas manifestações dos } \\
\text { seus praticantes e que foram reproduzidas } \\
\text { pelos participantes do projeto desde a } \\
\text { escolha das músicas até os figurinos } \\
\text { utilizados nas apresentações. }\end{array}$ & 18 & 100 \\
\hline & $\begin{array}{l}\text { b)Não foi possível resgatar nenhum } \\
\text { conhecimento histórico-cultural visto que } \\
\text { não tive a percepção dessas linguagens e } \\
\text { saberes no projeto de extensão. }\end{array}$ & 0 & 0,0 \\
\hline & $\begin{array}{l}\text { c)Houve o } \quad \text { resgate } \\
\text { conhecimentos de poucos } \\
\text { populares, visto que nem todas as } \\
\text { vivências tinham relação com a prática da } \\
\text { dança como executada pelos povos } \\
\text { praticantes. }\end{array}$ & 0 & 0,0 \\
\hline \multirow[t]{3}{*}{$\begin{array}{l}\text { Ampliação das } \\
\text { capacidades de } \\
\text { expressão e } \\
\text { comunicação } \\
\text { dos } \\
\text { extensionistas. }\end{array}$} & $\begin{array}{l}\text { a)Sim, com a dança possuo agora maior } \\
\text { capacidade de me expressar } \\
\text { corporalmente bem como, de entender os } \\
\text { significados da linguagem corporal por } \\
\text { meio dos gestos, movimentos e } \\
\text { expressões faciais. }\end{array}$ & 17 & 94,4 \\
\hline & $\begin{array}{l}\text { b)Não, não houve nenhuma mudança } \\
\text { quanto às minhas capacidades de } \\
\text { expressão depois da inserção no projeto. }\end{array}$ & 0 & 0,0 \\
\hline & $\begin{array}{l}\text { c)Parcialmente, minhas capacidades } \\
\text { comunicativas e expressivas mudaram em } \\
\text { poucos aspectos. }\end{array}$ & 1 & 5,5 \\
\hline
\end{tabular}

Fonte: a pesquisa (2020).

Com base nesses conhecimentos propiciado pelas experiências do projeto, 100\% (18/18) dos participantes mostraram que acreditavam ser importante o ensino das danças populares no seu processo de formação universitária. Esse mesmo quantitativo ver-se na questão referente ao envolvimento da comunidade com a dança, onde eles responderam que a dança integrando lazer, inclusão social e cultura é capaz de cativar a participação da população. Além disso, 94,4\% (17/18) apontaram o conhecimento do conteúdo histórico no aprendizado das danças populares como sendo indispensável. Essas informações encontram-se detalhadas no quadro 4.

Quadro 4 - Conhecimentos e saberes assimilados através do projeto de extensão

\begin{tabular}{|c|l|c|c|}
\hline $\begin{array}{c}\text { Perfil da } \\
\text { pergunta }\end{array}$ & \multicolumn{1}{|c|}{ Alternativas } & $\begin{array}{c}\text { Frequênci } \\
\text { a }\end{array}$ & (\%) \\
\hline & $\begin{array}{l}\text { a)Sim, pois proporcionar aos alunos da } \\
\text { graduação experiências com as danças } \\
\text { populares viabiliza a socialização, a }\end{array}$ & 18 & 100 \\
\hline
\end{tabular}




\begin{tabular}{|c|c|c|c|}
\hline \multirow{3}{*}{$\begin{array}{l}\text { Importância } \\
\text { do ensino da } \\
\text { dança popular } \\
\text { na formação } \\
\text { acadêmica. }\end{array}$} & $\begin{array}{l}\text { criatividade, o conhecimento histórico- } \\
\text { cultural de nossas raízes produzindo um } \\
\text { profissional mais capacitado nas suas } \\
\text { formas de expressão e comunicação. }\end{array}$ & & \\
\hline & $\begin{array}{l}\text { b)Não, pois dançar é uma atividade } \\
\text { corporal dentre várias outras e } \\
\text { dispensável à formação do indivíduo } \\
\text { enquanto aluno da graduação. }\end{array}$ & 0 & 0,0 \\
\hline & $\begin{array}{l}\text { c)Parcialmente, acredito que o ensino das } \\
\text { danças populares pode ser restringido } \\
\text { apenas aos cursos em que a dança faça } \\
\text { parte da sua área de atuação. }\end{array}$ & 0 & 0,0 \\
\hline \multirow{3}{*}{$\begin{array}{l}\text { Envolvimento } \\
\text { na prática da } \\
\text { dança pela } \\
\text { comunidade }\end{array}$} & $\begin{array}{l}\text { a)Envolve a comunidade quando } \\
\text { realizada com base na inclusão e na } \\
\text { promoção do lazer e da cultura } \\
\text { simultaneamente. }\end{array}$ & 18 & 100 \\
\hline & $\begin{array}{l}\text { b)Não envolve a comunidade, visto que a } \\
\text { dança por si só não é fator atrativo à sua } \\
\text { prática. }\end{array}$ & 0 & 0,0 \\
\hline & $\begin{array}{l}\text { c)Envolve apenas pelos benefícios a } \\
\text { saúde. }\end{array}$ & 0 & 0,0 \\
\hline \multirow{3}{*}{$\begin{array}{l}\text { Relevância do } \\
\text { conteúdo } \\
\text { histórico } \\
\text { vinculado ao } \\
\text { conhecimento } \\
\text { das danças } \\
\text { populares. }\end{array}$} & $\begin{array}{l}\text { a)Indispensável, porque permite ter a } \\
\text { compreensão sociocultural e histórica de } \\
\text { um povo, bem como o reconhecimento do } \\
\text { próprio corpo e suas relações no contexto } \\
\text { da dança. }\end{array}$ & 17 & 94,4 \\
\hline & $\begin{array}{l}\text { b) Irrelevante, pois é possível verificar } \\
\text { significados na historicidade de um povo } \\
\text { através de muitas outras ações, portanto, } \\
\text { o conhecimento das suas expressões } \\
\text { rítmicas e expressivas é dispensável. }\end{array}$ & 0 & 0,0 \\
\hline & $\begin{array}{l}\text { c)Relativamente importante, visto que há } \\
\text { outras manifestaçôs como as lutas } \\
\text { corporais, a religião, a música que gozam } \\
\text { de maior prestígio para o entendimento } \\
\text { sociocultural de um povo do que as } \\
\text { danças. }\end{array}$ & 1 & 5,5 \\
\hline
\end{tabular}

Fonte: a pesquisa (2020).

As questões com possibilidades de resposta aberta solicitavam aos discentes que 1) comentassem através de suas experiências no projeto como este oportunizou um maior entendimento acerca das danças populares e das manifestações culturais e 2) qual a visão deles sobre o Brincantes do Agreste como projeto de extensão. Ao todo houveram 36 respostas onde cada unidade de registro foi quantificada e trazida na tabela abaixo.

Tabela 1- Relação entre compreensão de dança e atividades de extensão

\begin{tabular}{ccc}
\hline Subcategorias & Frequência & $\mathbf{N}(\mathbf{\%})$ \\
\hline Cultura popular & 25 & $32,89 \%$ \\
Aquisição de novos & 18 & $23,68 \%$ \\
conhecimentos & 7 & $9,21 \%$ \\
Troca de experiências & 7 &
\end{tabular}




$\begin{array}{ccc}\text { Relações interpessoais } & 9 & 11,84 \% \\ \text { Saúde e autocuidado } & 7 & 9,21 \% \\ \text { Criticidade } & 9 & 11,84 \% \\ \text { Prática pedagógica } & 1 & 1,31 \% \\ \text { TOTAL: } & 76 & 100 \%\end{array}$

Fonte: a pesquisa (2020).

Direcionou-se o olhar para as categorias cultura popular e aquisição de novos conhecimentos que obtiveram maior unidade de registros, pois, não se pretende tratar exaustivamente de cada tópico, mas tecer uma reflexão acerca das categorias de maior relevância para a pesquisa e, expressa nas respostas dos participantes, refletindo nesse sistema de categorias as intenções da investigação (BARDIN, 2011).

Referente ao conteúdo cultura popular, essa categoria apresentou maior frequência nas respostas, destaca-se que o projeto possibilitou aos discentes adentrarem nas suas próprias raízes culturais, e que este não se restringe ao mero dançar, mas que traz conhecimento cultural e histórico nas suas atividades desenvolvidas.

Acerca da categoria "aquisição de novos conhecimentos", esta foi a segunda mais mencionada entre as respostas dos discentes em se tratando do processo de ensino-aprendizagem na extensão universitária. Síveres (2013) afirma que a extensão é uma forma de diálogo e uma possibilidade de aprendizado de conhecimentos articulados com os projetos da instituição. $\mathrm{Na}$ produção e comunicação desse conhecimento é que os sujeitos podem usufruir de uma melhor qualidade de vida fundamentada na ética, justiça e verdade.

\section{DISCUSSÃO}

As evidências encontradas nesta investigação indicaram que $100 \%$ dos participantes desta pesquisa tiveram suas experiências com danças ampliadas e maior entendimento sobre danças populares após sua inserção, além de terem a oportunidade de construírem novos conhecimentos nas relações entre os integrantes e a comunidade. Os resultados mostraram que os discentes visualizaram as suas experiências de levar à comunidade os conhecimentos desenvolvidos como uma atitude transformadora, e, consequentemente, provocar um impacto positivo no público-alvo do projeto.

Através do questionário percebeu-se que todos, depois de sua inserção, enxergavam como importante o ensino da dança popular como parte de sua formação acadêmica, dado que indica a relevância da extensão como propiciadora de práticas que o discente só terá aproximação fora da sua matriz curricular obrigatória. Como afirma Molina, Almeida e Dias (2013), a extensão 
oportuniza vivenciar diversas experiências que em muitas vezes estão distantes de suas disciplinas curriculares.

Almeida e Sá (2013) defendem que para que o processo educativo da extensão possa gerar resultados efetivos faz-se necessário uma articulação permanente com o ensino e a pesquisa favorecendo diálogos interdisciplinares. Além disso, como apontado pelos extensionistas, o trabalho com a dança folclórica requer uma apresentação do contexto de sua criação, pois conhecer os elementos que fazem parte de sua manifestação enriquecem o seu aprendizado e valorizam a produção cultural, ao invés de fazer uma mera reprodução desprendida de sentido.

O conteúdo cultura popular teve um destaque para os discentes, especialmente quando relacionado à questão da sua diversidade e da importância de conhecê-la. Constatou-se que esse trabalho com as danças populares motiva e traz uma nova perspectiva ao discente acerca de sua própria identidade cultural. Além disso, o projeto Brincantes do Agreste também se propõe a difundir essas danças para além do conhecimento cultural das manifestações pernambucanas, numa concepção que visa simultaneamente a aproximação dos discentes com a dança numa perspectiva artística e teatral.

A dança, como defende Marques (1989), muito mais do que uma vivência prática que permite expressar-se e acalmar as emoções, é capaz de propiciar uma percepção crítica diferenciada da própria prática e das nossas relações com o mundo e conosco mesmo. A dança como conhecimento é essencial na formação discente, permitindo compreender as relações do corpo no meio social, político, religioso e cultural de nossa sociedade. Nesse contexto, o conteúdo histórico é um dos elementos básicos para entendermos as danças de caráter popular, como defende Oliveira (1991) só é possível entendermos uma linguagem de dança através da reflexão do contexto social e histórico que os movimentos foram criados.

Durante as aulas de dança realizadas no projeto, também foi observado a utilização dos nomes dos passos no processo de ensino das coreografias, como "caruaru", "baiana" e "louvação", termos que fazem parte do vocabulário do Maracatu, estilo de dança trabalhado pelo grupo, além da utilização de músicas de caráter popular, demonstrando que a dança popular articula várias linguagens artísticas e não pode ser apreciada separada do conjunto de aspectos em que ela se insere. Como afirma Monteiro (2011, p. 45) “[...] o conteúdo motor da movimentação dos bailarinos está profundamente integrado a um todo artístico maior, e por isso, não se separa da compreensão de passos, coreografia e arte corporal do improviso poético, do canto e da percussão", por isso, não se deve pensar a dançar desvinculada do contexto onde ela é criada, utilizada e reproduzida.

Essa articulação de conhecimentos vinculada ao trabalho com diferentes pessoas é fundamental para tornar o estudante um profissional mais humano e atento a pensar no coletivo, 
esse aspecto também foi observado no ensaio, onde que os estudantes se ajudavam mutuamente no aprendizado dos passos e na própria organização dos momentos, o que proporciona ganhos de autoconfiança, autoestima, e conforto relacionado aos colegas para expressar corporalmente melhor seus sentimentos.

Para Oliveira (1991) essa atitude de criação ou recriação das manifestações folclóricas é capaz de reafirmar as crenças, valores e concepções de mundo de um determinado povo. Foi ainda apontado pelos alunos o benefício de expandirem essas manifestações artísticas à toda a universidade e à população em geral, e avivar a arte popular nos nossos dias fazendo com que as pessoas tenham a oportunidade de apreciá-la.

Destaca-se também a relação indissociável da prática da dança com o aumento da qualidade de vida, visto que, por meio da prática há uma aquisição valências físicas, além do impacto do ponto de vista estético e do autoconhecimento do discente (SZUSTER, 2011; ANDRADE et al., 2015), aumentando também a percepção do seu estado de saúde e capacidade de participação em atividades importantes para a sua vida, impactando positivamente a integração em atividades acadêmicas.

A extensão e a dança se complementam nesse sentido, por apresentarem um caráter que viabiliza a construção de conhecimento por meio de experiências diferenciadas entre sujeitos diversos em um contexto comum. Ademais, o projeto de extensão em dança reafirma a saúde como fator imprescindível à qualidade de vida e o bem-estar dos discentes. A isso Andrade et al. (2015) acrescentam que através do movimento e experimentação do corpo há uma maior percepção do indivíduo sobre si mesmo, além de sentimentos que interferem na sua própria percepção corporal e qualidade de vida.

Os resultados deste estudo corroboram com outras pesquisas como a de Nozaki, Pereira e Hunger (2015), Ribeiro, Pontes e Silva (2017) e Santos, Rocha e Passaglio (2015), mostrando que se faz necessário articular os conhecimentos produzidos na universidade com o contexto de vida em que esses saberes serão aplicados, e a extensão universitária deve assumir uma atitude de valorização dos saberes plurais numa aproximação com a sociedade, mostrando que a universidade, através dos projetos, deve atender à necessidade de uma formação ética, humanizada e interdisciplinar, ao qual tem na extensão umas das principais ferramentas para responder a esse propósito. 


\section{CONCLUSÃO}

Constatou-se que as práticas desenvolvidas pelo projeto Brincantes do Agreste permitiram apontar a importância da dança como objeto de conhecimento e experimentação, mostrando-se relevante no currículo devido à viabilidade de conhecimento histórico-cultural, melhor qualidade de vida nos aspectos biopsicossociais e por conter um caráter socializador em sua prática, culminando numa ampliação do entendimento sobre dança dos estudantes da ASCES-UNITA. As respostas apontaram que a realização comprometida de um projeto de extensão promove uma aprendizagem aprofundada nas especificidades da dança e atua como facilitador para a aquisição de novos saberes, uma vez que aproxima o conhecimento prático e contextualizado que, no caso do projeto desta pesquisa, traz um olhar direcionado para os movimentos não se restringindo aos aspectos motores, mas ao desenvolvimento da criticidade com relação às atividades buscando compreender os significados para além do ato de dançar.

Considerou-se que o Brincantes do Agreste insere-se como colaborador para a formação da concepção de dança dos discentes e da propagação das manifestações populares pernambucanas na sociedade baseado na intervenção. Entretanto, um número maior de encontros para analisar a rotina dos ensaios e uma coleta de dados que possibilite melhor analisar as percepções dos mesmos acarretaria em informações e discussões ainda mais profundas, bem como fazem-se necessários mais estudos na área para ampliar as investigações relacionadas a essa temática oportunizando a superação de paradigmas acerca das concepções de dança formadas pelos discentes e pela sociedade.

\section{REFERÊNCIAS}

VII CONGRESSO SULBRASILEIRO DE CIÊNCIAS DO ESPORTE. 2016, Criciúma. Extensão universitária e formação inicial em Educação Física: construindo saberes em dança. Universidade Comunitária da Região de Chapecó (Unochapecó). 2016.

ALMEIDA, Luciane Pinho de; SÁ, Salette Marinho de. Formação profissional no século 21: reflexões sobre aprendizagens a partir da extensão universitária. In: SÍLVERES, Luiz (Org.). A extensão universitária como princípio da aprendizagem. Brasília: Liber Livro, 2013.

AMARAL, Jaime. Das danças rituais ao ballet clássico. Revista Ensaio Geral. Belém, v.1, n.1, jan-jun de 2009. Disponível em: https://docplayer.com.br/21040614-Das-dancas-rituais-ao-ballet-classico-jaimeamaral.html. Acesso em: 01 de abr. de 2020.

ANDRADE, Luana Foroni; COIMBRA, Marli Aparecida Reis; CARBINATTO, Michele Viviene; MIRANZI, Mário Alfredo Silveira; PEDROSA, Leila Aparecida Kauchakje. Promoção da saúde: benefícios 
através da dança. Revista Família, Ciclos de Vida e Saúde no Contexto Social. Uberaba, v. 3, n. 3, set/dez, 2015, p. 228-234. Disponível em: https://www.redalyc.org/articulo.oa?id=497950366008. Acesso em: 30 jul. 2020.

BARDIN, Laurence. Análise de conteúdo. Lisboa: Edições 70, 2011.

BENETTI, Pablo Cesar; SOUSA, Ana Inês; SOUZA, Maria Helena do Nascimento. Creditação da extensão universitária nos cursos de graduação: relato de experiência. Revista Brasileira de Extensão Universitária. Rio de Janeiro. v. 6, n. 1, p. 25-32 jan/jun. 2015. Disponível em:

https://doaj.org/article/e5f41b3a672d45f4af347b5fd23189e2. Acesso em: 30 jul. 2020.

BRANDÃO, Carlos Rodrigues. O que é folclore. São Paulo: Brasiliense, 1983.

BRASIL, Constituição (1968). Constituição da República Federativa do Brasil de 1968. Brasília, DF: Presidência da República. Disponível em: http://www.planalto.gov.br/ccivil 03/leis/L5540.htm. Acesso em: 23 de mar. de 2020.

BRASIL, Constituição (1988). Constituição da República Federativa do Brasil. Brasília, DF: Senado Federal.

BRASIL, Lei no 9.394, de 20 de dezembro de 1996. Lei de Diretrizes e Bases da Educação Nacional. Diário Oficial da União, Brasília, DF, 24 dez. 1996. Disponível em:

http://www.planalto.gov.br/ccivil 03/leis/19394.htm. Acesso em: 29 mar. de 2020.

BRASIL, Ministério da Saúde. Gabinete do Ministro. Portaria no 2446, de 11 de novembro de 2014.

Redefine a Política Nacional de Promoção da Saúde (PNPS). Diário Oficial da União, Brasília, DF, 12 dez. 2014. p. 32.

BRASIL, Ministério da Saúde. Secretaria de Vigilância em Saúde. Secretaria de Atenção à Saúde. Política Nacional de Promoção da Saúde. 3. ed. Brasília: Ministério da Saúde, 2010.

CASTRO, Luciana Maria Cerqueira. A universidade, a extensão universitária e a produção de conhecimentos emancipadores. In: REUNIÃO ANUAL DA ANPED, 27., Caxambu, 2004. Anais...

Caxambu: ANPEd, 2004. Disponível em: http://www.anped.org.br/reunioes/27/inicio.htm. Acesso em: 02 de Janeiro de 2020.

COELHO, France Maria Contijo. A arte das orientações técnicas no campo: concepções e métodos. 2. ed. Viçosa: Suprema Gráfica, 2014.

COSTA, Aline Aparecida Cezar; BAIOTTO, Cléia Rosani; GARCES, Solange Beatriz Billig. Aprendizagem: o olhar da extensão. In: SÍLVERES, Luiz (Org.). A extensão universitária como princípio da aprendizagem. Brasília: Liber Livro, 2013.

DEUS, Sandra de Fátima Batista de. A valorização da Extensão universitária no Brasil. Entrevista concedida a Geraldo Ceni Coelho. Revista Brasileira de Extensão Universitária, v. 8, n. 2, p. 121-124, 2017. Disponível em: https://periodicos.uffs.edu.br/index.php/. Acesso em: 30 jul. 2020.

GARCIA, Berenice Rocha Zabbot; BOHN, Letícia Ribas Diefenthaeler; ARAÚJO, Maria Inês Siqueira. Universidade e extensão universitária: uma relação dialógica entre formação profissional e compromisso social. In: SÍLVERES, Luiz (Org.). A extensão universitária como princípio da aprendizagem. Brasília: Liber Livro, 2013.

KLEINUBING, Neusa Dendena; DAL CIN, Jamile. Formação inicial em Educação Física e a construção de saberes em dança: relações com a extensão universitária. Motrivivência. Florianópolis. v. 32, n. 62, p. 01- 
16, abril/junho, 2020. Disponível em: https://periodicos.ufsc.br/index.php/motrivivencia/article/view/21758042.2020e66195. Acesso em: 30 jul. 2020.

KLEINUBING, Neusa Dendena; PAULA, Samuel de; FRANCISCHI, Vanessa Gertrudes. Extensão universitária e a formação inicial em Educação Física: construindo saberes em dança. In: VIII Congresso Sulbrasileiro de Ciências do Esporte > VIII Congresso Sulbrasileiro de Ciências do Esporte. Criciúma/SC. Anais. 2016.

MARBÁ, Romolo Falcão; SILVA, Geusiane Soares da; GUIMARÃES, Thamara Barbosa. A dança na promoção da saúde e melhoria na qualidade de vida. Revista Científica do ITPAC, Araguaína, v.9, n.1. Fevereiro 2016.

MARINHO, Cristiane Moraes; FREITAS, Helder Ribeiro; COELHO, France Maria Gontijo; CARVALHO NETO, Moisés Felix de. Por que ainda falar e buscar fazer extensão universitária? Revista de Extensão da UNIVASF, Petrolina, v.7, n.1, p.121-140, 2019. Disponível em:

https://www.periodicos.univasf.edu.br/index.php/extramuros/article/view/942. Acesso em: 31 jul. 2020.

MARQUES, Isabel. Dance in the curriculum: the Brazilian case. Dissertação de Mestrado. Laban Centre for Movement and Dance, 1989.

MOLINA, Rinaldo Brito Regina Pires de; ALMEIDA, Cleverson Pereira de; DIAS, Patrícia Aparecida. Extensão universitária e formação profissional: a expressão de estudantes universitários. In: SíLVERES, Luiz (Org.). A extensão universitária como princípio da aprendizagem. Brasília: Liber Livro, 2013.

MONTEIRO, Marianna Francisca Martins. Dança popular: espetáculo e devoção. São Paulo: Terceiro Nome. 2011.

NANNI, Dionísia. O Ensino da Dança na Estruturação/Expansão da Consciência Corporal e da Autoestima do Educando. Fitness and Performance Journal, Rio de Janeiro - RJ, v. 4, n.1, p. 45-57, 2005.

NASCIMENTO, Marta José Rocha de Souza. A dança e a mudança de comportamento. Dissertação (Mestrado em Ciências da Educação) - Curso de Mestrado em Ciência da Educação, Universidade Lusófona de Humanidades e Tecnologias, Lisboa, 2012.

NOSAKI, Joice Mayumi; FERREIRA, Lilian Aparecida; HUNGER, Dagmar Aparecida Cynthia França. Evidências formativas da extensão universitária na docência em Educação Física. Revista Eletrônica de Educação, v. 9, n. 1, p. 228-241, 2015. Disponível em:

http://www.reveduc.ufscar.br/index.php/reveduc/article/viewFile/1175/390. Acesso em 02 de abr. de 2020.

OLIVEIRA, Maria Goretti Rocha de. Danças populares como espetáculo público no Recife, de 1979 a 1988. Recife: O Autor, 1991.

OLIVEIRA, Maria Goretti Rocha de. FREVO: Uma apresentação coreológica. Recife: Richard Veiga, 2017.

RIBEIRO, Mayra Rodrigues Fernandes; PONTES, Verônica Maria de Araújo; SILVA, Etevaldo Almeida. As contribuições da extensão universitária na formação acadêmica: desafios e perspectivas. Revista

Conexão. Ponta Grossa, v. 13 n.1. jan./abr. de 2017. Disponível em:

http://www.revistas2.uepg.br/index.php/conexao. Acesso em: 30 mar. 2020.

SANTOS, João Henrique de Sousa. ROCHA, Bianca Ferreira Rocha; PASSAGLIO, Kátia Tomagnini. Extensão Universitária e Formação no Ensino Superior. Revista Brasileira de Extensão Universitária. Belo Horizonte. v. 7, n. 1, p.23-28 jan/jun. 2016. Disponível em:

https://www.researchgate.net/publication/337724812 EXTENSAO UNIVERSITARIA E FORMACAO N O ENSINO SUPERIOR. Acesso em: 30 jul. 2020. 
SÍVERES, Luiz. A extensão como princípio de aprendizagem. Diálogos, vol. 10, 2008. Disponível em: https://portalrevistas.ucb.br/index.php/RDL/article/view/1946. Acesso em: 29 jul. 2020.

SÍVERES, Luiz. O princípio da aprendizagem na extensão universitária. In: SÍVERE, Luiz (Org.). A extensão universitária como princípio da aprendizagem. Brasília: Liber Livro, 2013.

SZUSTER. Lia. Estudo qualitativo sobre a dança como atividade física em mulheres acima 50 anos.69 f. (Monografia de Bacharel em Educação Física) Porto Alegre - RS.2011. Disponível em: https://www.lume.ufrgs.br/handle/10183/39328. Acesso em: 29 de março de 2020.

\section{NOTAS DE AUTOR}

AGRADECIMENTOS - Não se aplica.

CONTRIBUIÇÃO DE AUTORIA - Não se aplica.

FINANCIAMENTO - Não se aplica.

CONSENTIMENTO DE USO DE IMAGEM - Não se aplica.

APROVAÇÃO DE COMITÊ DE ÉTICA EM PESQUISA

Esta pesquisa foi aprovada pelo Comitê de Ética em Pesquisa (Parecer nº 3.745.077/2019).

CONFLITO DE INTERESSES - Os autores declaram não haver conflito de interesses.

\section{LICENÇA DE USO}

Os autores cedem à Motrivivência - ISSN 2175-8042 os direitos exclusivos de primeira publicação, com o trabalho simultaneamente licenciado sob a Licença Creative Commons Attribution Non-Comercial ShareAlike (CC BY-NC SA) 4.0 International. Esta licença permite que terceiros remixem, adaptem e criem a partir do trabalho publicado, desde que para fins não comerciais, atribuindo o devido crédito de autoria e publicação inicial neste periódico desde que adotem a mesma licença, compartilhar igual. Os autores têm autorização para assumir contratos adicionais separadamente, para distribuição não exclusiva da versão do trabalho publicada neste periódico (ex.: publicar em repositório institucional, em site pessoal, publicar uma tradução, ou como capítulo de livro), com reconhecimento de autoria e publicação inicial neste periódico, desde que para fins não comerciais e compartilhar com a mesma licença.

\section{PUBLISHER}

Universidade Federal de Santa Catarina. Programa de Pós-Graduação em Educação Física. LaboMídia - Laboratório e Observatório da Mídia Esportiva. Publicado no Portal de Periódicos UFSC. As ideias expressadas neste artigo são de responsabilidade de seus autores, não representando, necessariamente, a opinião dos editores ou da universidade.

\section{EDITORES}

Mauricio Roberto da Silva, Giovani De Lorenzi Pires, Rogério Santos Pereira.

\section{EDITOR DE SEÇÃO}

Juliano Silveira 


\section{REVISÃO DO MANUSCRITO E METADADOS}

João Caetano Prates Rocha; Keli Barreto Santos.

\section{HISTÓRICO}

Recebido em: 17 de setembro de 2020.

Aprovado em: 10 de novembro de 2020. 